\title{
The Effect of Drama Types and Brand Familiarity on Brand Attitude in Brand Placement
}

\author{
Ziying Liu, Ding Pan, Ya Xu \\ School of Management, Jinan University, Guangzhou, China \\ Email: liuziying925@163.com
}

How to cite this paper: Liu, Z.Y., Pan, D. and Xu, Y. (2019) The Effect of Drama Types and Brand Familiarity on Brand Attitude in Brand Placement. American Journal of Industrial and Business Management, 9, 491-502.

https://doi.org/10.4236/ajibm.2019.93033

Received: February 14, 2019

Accepted: March 11, 2019

Published: March 14, 2019

Copyright $\odot 2019$ by author(s) and Scientific Research Publishing Inc. This work is licensed under the Creative Commons Attribution International License (CC BY 4.0).

http://creativecommons.org/licenses/by/4.0/

(c) (i) Open Access

\begin{abstract}
Recent years, with the popularity of the costume drama, brand placement began to appear in the costume drama, such as "vip.com" in drama "Fighter of the Destiny", and "Unifon" in the drama "Princess Agents". This phenomenon is very controversial while attracting eyeballs. The large amount of audience can bring exposure to the brand, but many views complain about its rigid, and reducing the brand attitude. Based on the above phenomena, this article builds up a theoretical model including drama types, brand familiarity and consumers' attitude toward implanted brand. We validate it through two empirical studies, and the results show that, for high-familiar brands, placement into modern dramas will result in more active brand attitudes than places into costume dramas; for low-familiar brands, there is no significant difference between the two. The research results enrich the existing theories of advertising implants. Besides, it also provides references for the exposure of brands in different brand cycles in television programs, in order to obtain the best publicity and economic benefits.
\end{abstract}

\section{Keywords}

Brand Placement, Costume Drama, Modern Drama, Brand Familiarity, Brand Attitude

\section{Introduction}

Ancient themes have been the hotspots of TV series for years. With the popularity of these costume dramas, the brand placement began to appear in the film and television dramas of the costumes. Intuitively, a wide audience can bring more exposure to the brand. However, is the context of the costume 
drama really suitable for brand placement? Will it have a positive impact on consumer brand attitudes? And what factors affect the consumer's branding attitude?

As a popular drama type, the costume drama has a wide market audience and is one of the most important implant fields for advertisers. However, for advertisers, the effect of implanting in costume dramas is still not clear, and there is no previous such research to help explain the cause and result of this phenomenon. Thus, this article introduces a new variable: the context of implantation, and pays attention to the influence of the time difference on the implanted brands, providing a new perspective for the research of brand placement. And we focus on the following questions: 1) How the types of dramas (costume and modern dramas) influence the impact of brand placement on consumer's brand attitudes? 2) Whether different types of brands have different brand placement effects? 3) And what is the internal mechanism of this effect?

To explore issues above, we reviewed the previous research about brand placement, information process fluency, and brand familiarity to develop our hypothesis and research model about the influence of drama types on brand placement, and then we design two empirical researches to validate these hypotheses.

\section{Theoretical Framework}

\subsection{Brand Replacement}

In general, brand placement refers to a marketing method that aims to incorporate commercial content with non-commercial mass media programs to increase brand exposure and enhance consumer's brand attitudes [1]. This article focuses on brand placement behavior under different drama types (costume/modern). The costume drama refers to the TV series with ancient times background, and wearing costumes and imitating the behavior of ancients, which contains general historical dramas and fictional ancient dramas, such as "Fighter of the Destiny", "Princess Agents" and so on. Modern dramas are derived from modern life, and they also advocate the integration of real life into film and television dramas. "Good Times" and "Ode to Joy" are typical representatives of modern dramas. Costume dramas and modern dramas represent the characteristics of different eras, and their context and information are significantly different.

The story information received by the viewers during watching time can satisfy their information needs, and the value of the program is thus perceived. However, brand placement is the extra information provided by the drama. It can have a positive impact on the brand only if it meets the information needs of the audience [2]. Specifically, if this information is consistent with the experience of the consumer, it will have a positive effect on consumer's brand attitude, but if it is contrary to the consumer's cognitive experience, the brand attitude will take a negative change. 


\subsection{Information Processing Fluency}

Consumers' attitudes toward brand placement are formed through the process of information, and the degree of process fluency affects the evaluation of the object [3]. For consumers, smooth information processing will lead to a positive emotion, thus forming a positive attitude and preference for the processing object [4]. For example, the fluency of the product information reading process enables consumers to have a positive emotional response to the product. On the contrary, when the external things are different from our cognition, it will affect the individual's information processing fluency, so that the individual has a negative attitude towards the processing object.

For consumers, the implanted advertisements are additional information attached to the dramas, which will affect consumers' information processing process, and thus affect their attitude towards branding. When the information is consistent with the consumer's perception, such as the implanted brand is consistent with the drama plot, consumers will generate relevant associations about the brand content, and the smooth process of information processing will enhance their positive attitude towards the brand. On the contrary, when the implanted brand information is inconsistent with the consumer's cognition, such as implanting bluntness, it will make consumers realize their own concepts, attitudes, and behavioral tendencies are being influenced by information disseminators, promptly using self-accumulated knowledge to explain, evaluate, and respond to advertisers' persuasive intentions, redefining their communication with dramas and brands. This unsmooth information processing process not only interrupts consumer's viewing process but also exposes the advertiser's commercial intent clearly, which may cause consumers to pick up the opportunity to criticize the advertising content, thus forming negative attitude towards the brand.

\subsection{Brand Familiarity}

Brand familiarity refers to the amount of product and brand knowledge that consumers gradually accumulate through direct or indirect products experience, and represents the brand association set in consumer memory [5]. The more consumers are exposed to a brand, the more information storage associated with the brand. And the more familiar the brand is, the more attention they will have to these brands and services [6]. Therefore, higher brand familiarity will make it easier for consumers to mobilize their persuasive knowledge and redefine the communication process, especially when a situation does not match the consumer's own existing perceptions.

In the research of product placement, familiar brands will help consumers accelerate more knowledge of the brand, and will pay more attention to the brands and services that they have heard of. So higher brand familiarity will result in faster brand retrieval and coding speeds, helping viewers recognize brands faster. Mau proved that compared with familiar brands, unfamiliar brands implant in 
video games will lead to more positive attitudes [7]. For movies, due to the existence of simple exposure effects, only unfamiliar brand implantation can positively influence brand attitudes.

\section{Hypothesis}

\subsection{The Impact of Drama Type on Brand Attitude}

The viewer's contextual perception of dramas will affect branding effects. Advertising is additional information attached to dramas, and it can have a positive impact on the brand only if it is consistent with the consumer's cognition. On the contrary, when the advertising information is inconsistent with the consumer's cognition, such as implanting bluntness, the consumer will feel discomfort and realize that their attitudes and behavioral tendencies are influenced by information disseminators, and will promptly launch persuasive knowledge. This unsmooth information processing process not only interrupts the consumer's viewing process but also clearly exposes business intentions, probably making consumer criticize the content and source of the advertisement, thus forming a negative attitude towards the brand [8].

From the time dimension, the context of the costume dramas is based on ancient stories, but the placement of the brand adds modern information which is inconsistent with the drama context, affecting audience's viewing experience, they will perceive the advertiser's persuasive attempt and enable persuasion knowledge to respond [9], this unsmooth information processing process will decline consumer's brand attitudes.

On the contrary, in modern dramas, the information provided by advertisers conforms to the context, which enables the audience to simultaneously process the information of the implanted advertisement and the drama plot. Further, the positive emotion of this smooth processing will shift to the brand attitude.

Thus, we can introduce this hypothesis:

$\mathrm{H} 1$ : Compared to costume dramas, branding into modern dramas will lead to a more positive brand attitude.

\subsection{The Impact of Brand Familiarity on Brand Attitude}

Brand familiarity is the degree of the product and brand knowledge that consumers gradually accumulate through direct or indirect experience and represents the brand association set in consumers' memory. The higher the brand familiarity, the wider the brand association in the minds, and the easier to influence information processing and brand evaluation.

In face of familiar brand placement, the audience will associate the brand through the brand name and identify the implanted advertisement. The more familiar with the brand, the more consumers know about this brand [10], and easier to perceive the advertiser's intention to implant, and will lead to negative brand attitudes [11]. On the contrary, when faced with less familiar implanting, consumers lack the prior brand association, and less likely to activate persuasion 
knowledge. Instead, they are more likely to use the implanted plot to understand the brand and improve the attitude towards the implanted brand.

Thus, we can introduce this hypothesis:

H2: Compare to familiar brands, implantation of unfamiliar brands leads to a more positive brand attitude.

\subsection{The Interaction Impact of Drama Type and Brand Familiarity on Brand Attitude}

Brand familiarity refers to the amount of product and brand knowledge that consumers gradually accumulate through direct or indirect products experience, and represents the brand association set in consumer memory [5]. The more consumers are exposed to a brand, the more information storage associated with the brand. And the more familiar the brand is, the more attention they will have to these brands and services [6].

For familiar brands, consumers have lots of brand knowledge [12]. So when familiar brands are implanted in costume dramas, consumers will be more likely to get aware of the era differences between modern brands and ancient contexts and perceive the persuasion intention of the advertiser, leading to a negative brand attitude [13]. But familiar brand implant into modern dramas will have different effects. Modern dramas reflect modern life, the brand's implantation is in line with the existing consumer's brand knowledge, and will not produce strong discomfort. Therefore, ad placement in modern dramas is unlikely to trigger negative reactions.

On the contrary, consumers lack relevant associations for unfamiliar brands, and their learning memory of brands is derived from the implanting plot of dramas [14]. Subconsciously, they will regard unfamiliar brands as the virtual brand in specific situations [11]. Therefore, whether in the costume or modern dramas, the persuasion intention of the advertiser is well concealed and will not have a negative impact on the brand attitude.

Thus, we can introduce this hypothesis:

H3: Drama type and brand familiarity have an interaction impact on consumer's brand attitudes. For familiar brands, compared with costume dramas, implanting into modern dramas can lead to more positive brand attitudes. For unfamiliar brands, there is no significant difference in the impact of implanting on modern or costume dramas.

\subsection{The Mediating Effect of Information Processing Fluency}

The information processing fluency refers to the subjective degree of difficulty for individuals to process information about an object. The difficulty of such information processing would affect the evaluation of this object.

Compared with modern dramas, the brand placement in costume dramas will make consumers generate a serious sense of cognitive dissonance, leading to unsmooth processing of the plot information and perceiving the brand's persuasive intention, thus activating persuasion knowledge and reducing the original 
attitude level. Especially the familiar brand is more likely to lead differentiated information processing and brand evaluation [14], consumers can identify the familiar implanting brand in the costume drama, and generate a sense of discomfort, this negative emotion will be attributed to the implanting brand, and ultimately lead to negative brand attitude.

Thus, we can introduce this hypothesis:

H4: Information processing fluency mediates the influence of drama types and brand familiarity on consumer's brand attitudes.

\subsection{The Research Model}

Based on the above hypothesis, we propose the following research model: Compared with costume dramas, brand implants into modern dramas will result in a more positive brand attitude (H1). Compared with high-familiarity brands, Low-familiarity brand implants will lead to a more positive brand attitude (H2). For high-familiarity brands, implanting into modern dramas will result in a more positive brand attitude than costume dramas, but for low-familiarity brands, there is no significant difference between implanting in costume dramas and modern dramas (H3). Information processing fluency plays a mediating role in the influence of drama types and brand familiarity on consumer's brand attitudes (H4). The overall research model is shown in Figure 1.

\section{Experiment}

Based on the previous literature, we propose four hypotheses, and validate these hypotheses through two experiments.

\subsection{Experiment 1}

\section{Design}

The purpose of Experiment 1 is to examine the impact of drama types, brand familiarity on consumer brand attitudes, and the interaction impact. To this end, we used 2 (drama types: costume/modern) $\times 2$ (brand familiarity: high/low) inter-group design, and added a control group without implanted advertisement as the benchmark data.

What's more, we recruit 180 participants from universities in Guangdong and Hubei province. All the participants aged between 18 and 40, and were randomly divided into one of four groups, each group consisting of 30 people, and each of the male and female participants was about 15 .

Process

Firstly, we asked the participants whether they had watched the experimental drama. If there is a drama recording, they would not participate in the formal experiment. Those who did not have drama experience would continue to watch a 5-minute experimental clip contained an implanted advertisement: The clips were all selected from well-known dramas, such as "Princess Agents", "Good Times", etc., and all contained a complete scene, without any obvious emotional tendency. 


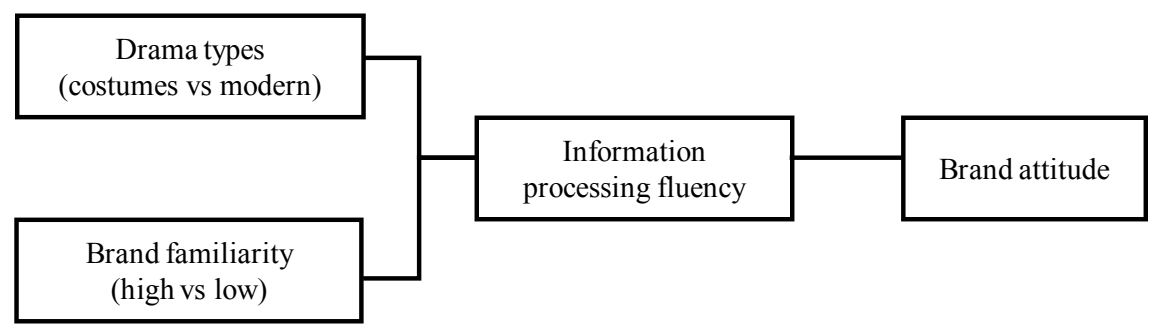

Figure 1. The impact of drama types and brand familiarity on consumer brand attitude.

Then, after watching experimental clips, all partners were asked to fill out the questionnaire to measure the brand familiarity [15] and the attitude towards the implanted brand [16]. In addition, in order to exclude other explanations, we also measured the degree of product involvement and the popularity of the drama. After completing all the experimental sessions, 5 yuan was given to each participant as the payment.

\section{Result}

In experiment 1, 166 valid questionnaires were collected, of which males accounted for $47.3 \%$.

Manipulation check: "vip.com" and "One Leaf" have significant differences in the score of brand familiarity $\left(\mathrm{M}_{\text {vip.com }}=5.848, \mathrm{M}_{\text {One Leaf }}=2.412, \mathrm{t}=22.503, \mathrm{P}<\right.$ $0.01)$. Secondly, there was no significant difference between the involvement score $(t=1.535, P>0.05)$, and no significant difference between the preference for four clips $(F(1,109)=0.661, P>0.05)$, indicating that the degree of product involvement and the popularity of dramas are well controlled.

Hypothesis test: We subtracted the mean value of the brand attitude scores of the experimental group and the control group, to form "brand attitude difference" as the dependent variable.

A $2 \times 2$ ANOVA on brand attitude reveal a significant main effect of drama types $(\mathrm{F}(1,109)=11.164, \mathrm{P}<0.001)$, and a significant main effect of brand familiarity $(\mathrm{F}(1,109) 26.648, \mathrm{P}=0.000)$, and the interaction between the two was also significant $(\mathrm{F}(1,109)=12.321, \mathrm{P}<0.01)$.

Specifically, compared to modern dramas, branding in the costume dramas will lead to a lower brand attitude $\left(\mathrm{M}_{\text {costume drama }}=-1.344 ; \mathrm{M}_{\text {modern drama }}=-0.120\right.$; $\mathrm{F}(1,109)=11.164, \mathrm{P}<0.01)$, supporting our hypothesis H1. Secondly, the implantation of unfamiliar brands leads to a more positive brand attitude than the familiar brands. $\left(\mathrm{M}_{\text {high familiarity }}=-1.616 ; \mathrm{M}_{\text {ow familiarity }}=0.162 ; \mathrm{F}(1,109)=26.648, \mathrm{P}\right.$ $<0.01$ ), supporting our hypothesis $\mathrm{H} 2$.

At the same time, there was a significant drama types $\mathrm{X}$ brand familiarity interaction $(\mathrm{F}(1,109)=12.321, \mathrm{P}<0.01)$, as shown in Figure 2 . Under high familiarity conditions, compared with modern dramas, branding in costume dramas significantly reduced participants brand attitude $\left(\mathrm{M}_{\text {costume drama }}=-2.707 ; \mathrm{M}_{\text {modern }}\right.$ drama $=-0.444 ; \mathrm{F}(1,109)=22.23, \mathrm{P}<0.01)$. In the case of low familiarity, there was no significant difference in brand attitudes $\left(\mathrm{M}_{\text {costume drama }}=0.120 ; \mathrm{M}_{\text {modern drama }}\right.$ $=0.204 ; \mathrm{F}(1,109)=0.03, \mathrm{P}>0.05)$, supporting our hypothesis $\mathrm{H} 3$. 


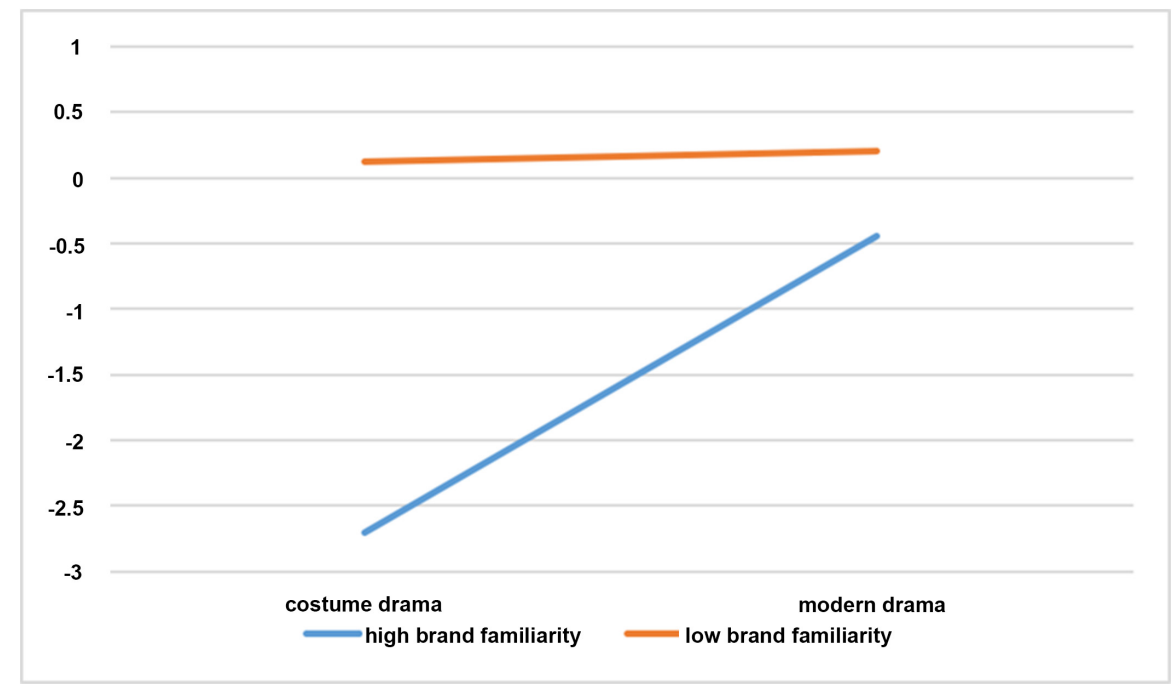

Figure 2. The interaction impact of drama types and brand familiarity on consumer brand attitude.

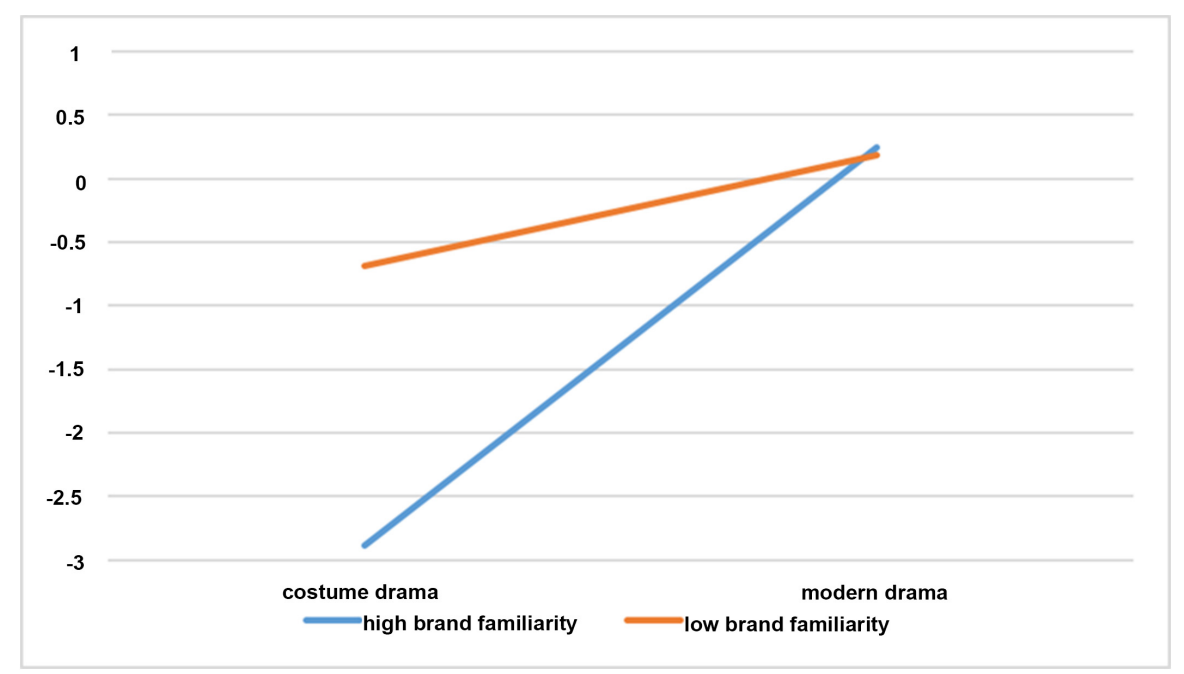

Figure 3. The interaction impact of drama types and brand familiarity on consumer brand attitude.

\section{Discussion}

Experiment 1 demonstrates that under high familiarity conditions, compared with modern dramas, branding in costume dramas significantly reduced participants brand attitude, but in the case of low familiarity, there was no significant difference in brand attitudes. As described above, we believe that findings occur precisely because consumers experienced different information processing process.

\subsection{Experiment 2}

\section{Design}

Experiment 2 also used 2 (drama types: costume/modern) $\times 2$ (brand familiarity: high/low) inter-group design to re-examine the interactive impact of 
drama types and brand familiarity on consumer brand attitude, and further, the mediating role of information processing fluency was analyzed. In this experiment, 180 participants were selected from a company in Shenzhen, and 166 valid questionnaires were collected.

\section{Process}

The procedure of Experiment 2 was roughly the same as Experiment 1. The subjects who had no previous viewing experience were randomly assigned to four groups and watched the corresponding video clips which contained the implanted advertisements. After watching the clip, we rated their brand familiarity, brand attitude, information processing fluency, and product involvement. Finally, we also recorded the individual characteristics of the subjects, including the measurement of statistical characteristics such as gender, age, and education. After completing all the experimental sessions, 5 yuan was given to each participant as the payment.

\section{Result}

Manipulation check: Brands with different familiarities have significant differences in brand familiarity scores ( $\mathrm{M}$ high familiarity $=5.947$, $\mathrm{M}$ low familiarity $=2.296, t=37.370, P<0.01)$, but no significant difference between the degrees of involvement $(t=0.769, P=0.444>0.05)$, the manipulation of brand familiarity was successful.

Main effect test: A $2 \times 2$ ANOVA on brand attitude reveal a significant main effect of drama types $(\mathrm{F}(1,110)=32.372, \mathrm{P}<0.01)$, and a significant main effect of brand familiarity $(\mathrm{F}(1,110)=7.683, \mathrm{P}<0.01)$, supporting our hypothesis $\mathrm{H} 1$ and $\mathrm{H} 2$. At the same time, the interaction between the two was also significant $(F(1,110)=11.826, P<0.01)$, as shown in Figure 3 . Under high familiarity conditions, compared with modern dramas, branding in costume dramas significantly reduced participants brand attitude $\left(\mathrm{M}_{\text {costume drama }}=-2.888 ; \mathrm{M}_{\text {modern drama }}=\right.$ $0.250 ; \mathrm{F}(1,110)=43.28, \mathrm{P}<0.01)$. In the case of low familiarity, there was no significant difference in brand attitudes $\left(\mathrm{M}_{\text {costume drama }}=-0.685 ; \mathrm{M}_{\text {modern drama }}=\right.$ $0.185 ; \mathrm{F}(1,110)=3.12, \mathrm{P}>0.05)$, supporting our hypothesis $\mathrm{H} 3$.

Mediation effect test: We conducted a mediated moderation analysis using information processing fluency as the mediator. First, we regressed brand attitude difference on drama types, brand familiarity, and their interaction. This analysis resulted in a significant interaction effect $(\beta=2.044, \mathrm{P}=0.000)$. Second, we regressed information processing fluency on drama types, brand familiarity, and their interaction, which revealed a significant interaction effect $(\beta=0.874, \mathrm{P}$ $=0.000$ ). Finally, we regressed brand attitude difference on drama types, brand familiarity, their interaction, and information processing fluency. The results revealed that the main effect of information processing fluency remained significant $(\beta=0.898, \mathrm{P}=0.000$ ), and significance of drama types $\mathrm{x}$ brand familiarity interaction declined $(\beta=1.259, \mathrm{P}=0.00)$.

We then conducted a bootstrapping analysis that generated a sample size of 5000 [17]. In supporting our hypothesis H4, a 95\% confidence interval (CI) for 
the indirect effect was significant and excluded zero (95\% CI: $-2.2378,-0.5895)$, which provided the evidence of the mediation effect of information processing fluency.

Demographic variables test: In this experiment, we further analyzed the effect of gender, age and education to exclude the interpretation of these variables. There was no significant effect of gender, age and education on consumer brand attitude (gender: $\mathrm{t}=-0.368, \mathrm{P}>0.05$; age: $\mathrm{F}=(1,110)=1.136, \mathrm{P}>0.05$; education: $\mathrm{F}(1,110)=0.326, \mathrm{P}>0.05)$. So we can rule out the impact of the basic demographic characteristics in this experiment.

\section{Discussion}

Experiment 2 re-examined the interactive impact of drama types and brand familiarity on consumer brand attitude, and further, we found the mediating role of information processing fluency. Thus, the research model was totally tested.

\section{General Discussion}

With the popularity of costume dramas, more and more brands choose to implant advertisements in costume dramas. However, is it really a good strategy for brands to implant advertisements in costume dramas?

In this paper, we conduct a comprehensive study on the research questions through the review of previous research and the design of empirical research. 1) Compared with modern drama, the brand implants in costume dramas will make consumers generate a sense of mismatch of the era of ancient costumes and modern brands, which may lead to negative brand attitudes. By contrast, implanting in modern dramas may not generate bad imagination. 2) Brands with high familiarity are more likely to be recognized by consumers, thus they perceived the persuasive intention and then reduced their brand attitude. While the consumers lack associative memory of the low-familiar brand and have not formed the existing cognition, placement will not have a negative impact on the brand. 3) For brands with different familiarities, the impact of implanted drama types on consumer brand attitudes is not the same. High familiarity brands are more likely to arouse consumers' associative memories, and they are more prone to cognitive dissonance in the case of costume drama implants, so lead to lower brand attitude. However, for low familiarity brands, consumers are more likely to treat the brand as a virtual brand in the situation and form their brand attitude, so no matter implants in costume or modern dramas, there is no significant difference in consumer brand attitude.

\section{Implication}

Previous research on brand placement did not pay attention to the influence of different drama contexts on the effect of brand placement. However, with the popularity of costume dramas, this research is getting more necessary, this paper fills this research gap and enriches the research of brand placement. Furthermore, we provide a reference for companies to set different exposure level in 
dramas for brands in the different stage of life cycles, to obtain the best publicity effect and economic benefits.

For companies, the development of the television industry is a good opportunity for brand marketing. The diversification of brand placement also expands the breadth and depth of the advertising channel continuously. However, both the advertisers and the brand side need to balance business interests and the production of sophisticated cultural content, to meet the need of audience, too straightforward and bluntly implanted methods will only generate a negative attitude towards the brand.

Costume dramas have a wide audience in the domestic market. Although brand placement would increase brand exposure, it may also have a negative impact on the brand itself, which is not conducive to the premium in the future. For brands that are familiar to consumers, although viewers can remember the brand through brand placement, they may have a negative impact on brand attitudes in modern drama implant conditions, and modern drama implants can be more acceptable.

For brands that are not familiar to the public, widely types of drama can be chosen, both costume dramas and modern dramas are suitable for brand placement to get more exposure, and to quickly open the market and enhance consumers' attitude towards the brand.

\section{Limits and future research}

Throughout the experiment, we used a variety of methods to increase the rigor of this paper, selecting rigorous materials and controlling the effects of related variables during the experiment. However, there are still some problems with this research. For the measurement of brand placement effects, we only focus on the changes in consumer brand attitudes, without further measuring the willingness of purchase, brand selection, etc., future research can the measure of these variables to increase the reliability of the conclusion.

\section{Conflicts of Interest}

The authors declare no conflicts of interest regarding the publication of this paper.

\section{References}

[1] Ginosar, A. and Faur, D.L. (2010) Regulating Product Placement in the European Union and Canada: Explaining Regime Change and Diversity. Journal of Comparative Policy Analysis Research \& Practice, 12, 467-490. https://doi.org/10.1080/13876988.2010.516512

[2] Van Reijmersdal, E., Smit, E. and Neijens, P. (2010) How Media Factors Affect Audience Responses to Brand Placement. International Journal of Advertising, 29, 279-301. https://doi.org/10.2501/S0265048710201154

[3] Winkielman, P., Schwarz, N., Fazendeiro, T., et al. (2003) The Hedonic Marking of Processing Fluency: Implications for Evaluative Judgment. In: Musch, J. and Klauer, K.C., Eds., The Psychology of Evaluation: Affective Processes in Cognition and 
Emotion, Psychology Press, Hove, 189-217.

[4] Schwarz, N. (2004) Metacognitive Experiences in Consumer Judgment and Decision Making. Journal of Consumer Psychology, 14, 332-348. https://doi.org/10.1207/s15327663jcp1404_2

[5] Lafferty, B.A. (2009) Selecting the Right Cause Partners for the Right Reasons: The Role of Importance and Fit in Cause-Brand Alliances. Psychology \& Marketing, 26, 359-382. https://doi.org/10.1002/mar.20277

[6] Dens, N. and De Pelsmacker, P. (2010) Advertising for Extensions: Moderating Effects of Extension Type, Advertising Strategy, and Product Category Involvement on Extension Evaluation. Marketing Letters, 21, 175-189. https://doi.org/10.1007/s11002-009-9086-1

[7] Mau, G., Silberer, G. and Constien, C. (2008) Communicating Brands Playfully: Effects of In-Game Advertising for Familiar and Unfamiliar Brands. International Journal of Advertising, 27, 827-851. https://doi.org/10.2501/S0265048708080293

[8] Janiszewski, C. (2001) Effects of Brand Logo Complexity, Repetition, and Spacing on Processing Fluency and Judgment. Journal of Consumer Research, 28, 18-32. https://doi.org/10.1086/321945

[9] Evans, N.J. and Park, D. (2015) Rethinking the Persuasion Knowledge Model: Schematic Antecedents and Associative Outcomes of Persuasion Knowledge Activation for Covert Advertising. Journal of Current Issues \& Research in Advertising, 36, 157-176. https://doi.org/10.1080/10641734.2015.1023873

[10] Verhellen, Y., Dens, N. and Pelsmacker, P.D. (2016) Do I Know You? How Brand Familiarity and Perceived Fit Affect Consumers' Attitudes towards Brands Placed in Movies. Marketing Letters, 27, 1-11. https://doi.org/10.1007/s11002-015-9347-0

[11] Matthes, J., Schemer, C. and Wirth, W. (2007) More than Meets the Eye: Investigating the Hidden Impact of Brand Placements in Television Magazines. International Journal of Advertising, 26, 477-503. https://doi.org/10.1080/02650487.2007.11073029

[12] Huang, G. (2016) Moderating Role of Brand Familiarity in Cross-Media Effects: An Information Processing Perspective. Journal of Promotion Management, 22, 665-683. https://doi.org/10.1080/10496491.2016.1154922

[13] Fransen, M.L., Verlegh, P.W.J., Kirmani, A., et al. (2015) A Typology of Consumer Strategies for Resisting Advertising, and a Review of Mechanisms for Countering Them. International Journal of Advertising, 34, 6-16. https://doi.org/10.1080/02650487.2014.995284

[14] Campbell, M.C. and Keller, K.L. (2003) Brand Familiarity and Advertising Repetition Effects. Journal of Consumer Research, 30, 292-304. https://doi.org/10.1086/376800

[15] Keller, K.L. (1993) Conceptualizing, Measuring, and Managing Customer-Based Brand Equity. The Journal of Marketing, 57, 1-22.

[16] MacKenzie, S.B. and Spreng, R.A. (1992) How Does Motivation Moderate the Impact of Central and Peripheral Processing on Brand Attitudes and Intentions? Journal of Consumer Research, 18, 519-529. https://doi.org/10.1086/209278

[17] Hayes, A.F. (2013) Introduction to Mediation, Moderation, and Conditional Process Analysis: A Regression-Based Approach. Journal of Educational Measurement, 51, 335-337. 